\title{
ÖZELLEŞTİRME VE ANAYASALAR ORTA AVRUPA DENEYIMI
}

\author{
Dr. Levent GÖNENÇ
}

\section{Giriş}

Doğu Avrupa'daki sosyalist rejimler ve Sovyet Sosyalist Cumhuriyetler Birliği (SSCB) 20. yüzyılın sonlarında büyük bir değişim geçirdi. Sosyal bilimler literatüründe "1989 Devrimi” olarak bilinen bu kapsamlı sosyal hareket, özellikle SSCB'de Komünist Parti Genel Sekreteri Mihail Gorbaçev'in başlattığ 1 ve sürdürdüğü reformlarla ivme kazandı. Kısa sürede Orta ve Doğu Avrupa'ya yayılan bu hareket II. Dünya Savaşı sonrasında oluşan iki kutuplu dünyanın sosyalist bloğunda yer alan rejimlerin bir biri ardına ortadan kalkmasıyla tepe noktasına ulaştı. Berlin duvarının yıkılmasıyla simgelenen bu büyük değişim sonucunda eski sosyalist blok ülkelerinde iki, hatta üç boyutlu bir dönüşüm gerçekleşti. Birincisi, SSCB, Orta ve Doğu Avrupa'daki otoriter veya totaliter rejimler yerini demokratik veya yarı-demokratik rejimlere bıraktı. İkincisi, bu ülkelerdeki sosyalist rejimler tarafindan benimsenen planlı ekonomi sisteminden pazar ekonomisi sistemine geçildi. Üçüncüsü, bazı ülkelerde (SSCB, Yugoslavya ve Çekoslovakya), çok-uluslu federal yapılar parçalanarak irili-ufaklı bağımsız devletlere vücut verdi (GÖNENÇ, 2002). Biz bu makalede, bu üçlü dönüşümün ekonomik yapıya ilişkin ayağı üzerinde durmak istiyoruz. Bunu yaparken kendimizi özellikle bu dönüşümün temel taşlarından biri olan özelleştirmenin anayasal boyutuyla sınırlayacağız. Bu çerçevede, özellikle bu ülkelerde tartışma konusu olan iki konuya değineceğiz: (1) Özelleştirme faaliyetlerinin zamanlaması ve anayasa yapım süreci arasındaki ilişki; (2) Özelleştirme faaliyetlerinin yürütülebilmesi için anayasalarda yer alması gereken düzenlemeler. Bu kısa çalışmanın sınırları içinde, bugün Avrupa Birliği üyesi olmaları ve özelleştirme konusunda diğer eski sosyalist ülkelere göre önde gitmeleri nedeniyle, dört Orta Avrupa ülkesi; Çek Cumhuriyeti, Slovakya, Macaristan ve Polonya üzerinde yoğunlaşacağız. 


\section{1) Özelleştime Faaliyetlerinin Zamanlamast ve Anayasa Yapım Süreci}

Eski sosyalist rejimlerde en çok tartışma konusu olan noktalardan biri anayasa yapım süreciyle özelleştirme uygulamalarının zamanlaması arasındaki ilişkiydi. Acaba özelleştirme faaliyetlerinin yeni (liberaldemokratik) anayasalar yapılmadan önce başlaması uygun olur muydu? Yoksa bu faaliyetlere girişmeden önce özelleștirmenin en temel hukuki çerçevesini çizecek olan anayasaların yapılmasını mı beklemek gerekiyordu? $\mathrm{Bu}$ konuda yapılan teorik tartışmalara baktığımızda esas olarak iki görüşün ağırlık kazandığını görüyoruz: Bir kısım yazar (örneğin, ELSTER, 1992; 1993), anayasayı, piyasa mekanizmalarını kurmayı hedefleyen ekonomik reform sürecinin başarıya ulaşabilmesi için siyasi ön-şart olarak görmekteydi. $\mathrm{Bu}$ yazarlara göre, anayasa devletin keyfi iktidarını sınırlayarak, ekonomik aktörlere serbestçe sözleşmelere katılma ve uzun vadeli yatırımlara girişme konusunda güven telkin edebilir, bu iki unsur ise ekonomik reformların başarıya ulaşması için gerekli şartları hazırlayabilirdi. Bir kısım yazar ise (örneğin, HOLMES, 1993/1994), ekonomik reformların uygulanabilmesi için alınması gereken kararların halk arasında hoşnutsuzluk yaratabileceğine dikkat çekmekteydi. Bu yazarlara göre, ekonomik reformlar siyasi iktidarların popülaritesini olumsuz yönde etkileyebilecek bazı radikal kararların alınmasını gerektiriyordu. Özellikle sosyalist rejim zamanında, devletten ekonomik menfaat beklemeye ve almaya alıșmış olan vatandaşların, bu "konforu" ellerinden alacak bir dizi düzenlemeyi kolaylıkla kabul etmesi beklenemezdi. Bu bağlamda, söz konusu yazarlar, halkın hoşuna gitmeyecek bu tür radikal kararları almak için güçlü siyasi iktidarlara ihtiyaç duyulacağının altını çizmekteydi. İşte, siyasi iktidarları sınırlamaya yönelik belli-başlı araçlardan biri olan anayasa, reformcuları geçiş döneminde etkin ve hızlı karar almak için gereken güçten yoksun bırakabilirdi. İlk yaklaşımı ortaya koyan yazarlar bir an önce bir anayasa yapılmasını savunurken, ikinci yaklaşımı ortaya koyanlar anayasa yapımının ekonomik dönüşümün gerçekleştirilmesinden sonraya ertelenmesini öneriyorlard1 (HELLMAN, 1996).

$\mathrm{Bu}$ teorik tartışmalar bir yana, uygulamaya baktığımızda genellikle özelleştirme faaliyetlerinin yeni anayasaların kabulünden önce başladığını görüyoruz. Örneğin, bugün yürürlükte olan anayasasını 1997 yılında kabul eden Polonya'nın özelleştirme uygulamaları 1990'lı yılların başından beri devam etmektedir. Aynı şekilde, yeni anayasalarını 1992 yılında kabul eden Çek ve Slovak cumhuriyetleri henüz ayrılmadan önce, Ocak 1991'de rekabete, 1992 'de ticarete ilişkin düzenlemeler yürürlüğe girmişti (AVENUES FOR INVESTMENT, 1993). Kuşkusuz özelleştirmeye ilişkin faaliyetlerin tamamiyle eski sosyalist anayasalar altında yürütülmesi de mümkün değildi. $\mathrm{Bu}$ yüzden söz konusu ülkeler, mevcut sosyalist anayasalarında özelleştirmeyi mümkün kılacak-özellikle mülkiyet hakkı ve özel girişim özgürlüğüne ilişkin — sınırlı sayıda anayasa değişikliği yapmayı, buna karşılık özelleştirme faaliyetleri açısından hayati öneme sahip 
yasalardaki değişikliklere ağırlık vermeyi tercih etmişlerdi. Mülkiyet, sözleşme, şirketler ve rekabet hukuku alanlarındaki kapsamlı yasal düzenlemeler yeni anayasalar kabul edilmeden bu ülkelerde özelleștirme faaliyetlerinin başlatılmasına imkan verdi (COHEN ve SCHWARTZ, 1994). Macaristan'ın önde gittiği Orta Avrupa'daki özelleștirme faaliyetleri yeni anayasaların kabulünden sonra da devam etti (ELSTER, OFFE ve PREUSS, 1998). Bütün bu uygulamalar toplu olarak değerlendirildiğinde, Joel Hellman'ın da isabetle belirttiği gibi, ekonomik reformların ve özelleştirmenin başlangıcı ile yeni anayasanın kabulü arasında herhangi bir bağlantı kurulması mümkün görünmemektedir (HELLMAN, 1996). Buna karşılık, aynı değerlendirmeyi ekonomik reformların sonuçları açısından tekrarlamak güçtür. Özellikle Rusya Federasyonu'nda Ocak 1992-Ekim 1993 yılları arasında gerçekleştirilen ekonomik reformlar ve özelleştirme faaliyetleri (ANGELOV, 1993), o dönemde siyasi iktidarı sınırlayacak, hesap vermesini sağlayacak anayasal mekanizmaların yokluğu nedeniyle, pek çoğu daha sonradan kanıtlanan yolsuzluk ve kayırma iddialarıyla gölgelendi (SACHS ve PISTOR, 1997; SACHS, WOO ve YANG, 2000).

Sonuç olarak, Orta ve Doğu Avrupa ve Rusya deneyimi birlikte ele alındığında, anayasal çerçevenin özelleştirme faaliyetlerinin başlaması açısından değil, bu faaliyetlerin, siyasi iktidarın belli gruplara menfaat sağlamasını engelleyebilecek hukuki sınırlar içinde yürütülmesi açısından önemli olduğu söylenebilir.

2) Özelleştirme Faaliyetlerinin Yürütülebilmesi İçin Anayasalarda Yer Alması Gereken Düzenlemeler

Eski sosyalist blok ülkelerinde gerçekleştirilen özelleştirme faaliyetlerinin anayasal boyutuyla ilgili olarak üzerinde durulması gereken bir başka konu, anayasaların bu faaliyetleri nasıl, hangi ölçüde düzenlemesi gerektiği sorusudur. Avrupa Konseyi bünyesindeki Venedik Komisyonu tarafindan bu konuda hazırlanan rapora göre, anayasalar piyasa ekonomisinin işlemesini mümkün k1lacak temel çerçeveyi kurmakla yetinmeli, ayrıntıları yasama ve yürütme organına bırakmalıdır. Anayasanın katı ve zor değiştirilebilir özelliği hızlı değişen piyasa şartlarının gerektirdiği esnekliği sağlamamakta, yasalar ve kararnameler ise ekonomik aktörlerin ihtiyaçlarına göre yasama ve yürütme organının gerekli tedbirleri almasına imkan vermektedir. Bu yüzden ayrıntıların anayasada belirlenmesi yerinde olmaz (HERBIET, 1994).

Gerçekten, Orta Avrupa anayasalarının ilgili hükümlerine baktığımızda, genel olarak bu raporda önerildiği gibi, genel bir çerçevenin çizildiğini ayrıntıların yasama ve yürütme organına bırakıldığını görüyoruz. Örneğin, Slovak Anayasası'nın 55/2. maddesi, Slovak Cumhuriyeti'nin, ekonomik rekabeti koruyacağını ve özendireceğini hükme bağlamaktadır. Aynı fıkraya göre, ayrıntılar yasa ile düzenlenecektir. Benzer şekilde, Macar Anayasası'nın 9. ve Polonya Anayasası'nın 20. maddeleri ayrıntıya inmeden 
piyasa ekonomisinin temel çerçevesini çizmekle yetinmektedir. Macar Anayasası'nın 9. maddesinin 1. fikrasına göre, Macaristan'ın ekonomisi, kamusal ve özel mülkiyetin eşit statü ve korunmaya sahip olduğu pazar ekonomisidir. Polonya Cumhuriyeti'nin ekonomik sisteminin temeli, ekonomik faaliyet özgürlüğü, özel mülkiyet, toplumsal taraflar arasındaki dayanışma, diyalog ve işbirliğine dayanan sosyal pazar ekonomisidir (Anayasa, m. 20).

Acaba özelleştirmeyi mümkün kılmak için anayasalarda hangi spesifik hak ve özgürlüklerin yer alması gerekir? Kuşkusuz günümüzde "özelleştirme" kavramı, piyasa ekonomisine geçişi öngören geniş bir kurumlar ve uygulamalar dizisini ifade etmek için kullanılmaktadır. Ancak Orta ve Doğu Avrupa açısından düşünüldüğünde, özelleştirmenin kendine özgü bir anlamı olduğuna da işaret etmek gerekir. Bojan Bugaric'in "radikal özelleştirme" adını verdiği Orta ve Doğu Avrupa'daki özelleştirme, bir yandan kamusal mülkiyetin özel mülkiyete dönüşümünü, diğer yandan devletin ekonomiden elini çekmesini ifade etmektedir (BUGARIC, 1999). $\mathrm{Bu}$ çerçevede değerlendirildiğinde, Orta ve Doğu Avrupa anayasalarında özelleştirme açısından tartışılması gereken iki temel konu olduğu söylenebilir: (1) Mülkiyet hakk1; (2) Özel girişim özgürlüğü ve devletin ekonomik hayata müdahalesinin sinırları.

(1) Mülkiyet Hakkı: Bu hak özelleștirmenin ön-şartı olarak görülebilir. Bireylerin mülkiyet edinme ve sahip oldukları mülkiyet üzerinde serbestçe tasarruf etme hakları olmadığı sürece, arz-talep dengesine dayanan piyasa mekanizmalarının işlemesi mümkün olamaz. Dolayısıyla, piyasa ekonomisine geçerken özel mülkiyetin tanınması ve anayasa ile garanti altına alınması hayati önem taşımaktadır (BALFOUR ve CRISE, 1993). Bu bağlamda, incelemekte olduğumuz dört anayasanın da, diğer post-komünist anayasalar gibi, mülkiyet hakkını tam olarak garanti altına aldığ 1 görülmektedir (Çek Cumhuriyeti Anayasası'na dahil Temel Haklar Şartı, m. 11; Slovak Anayasası, m. 20; Macar Anayasası, m. 13; Polonya Anayasası, m. 21). Bu anayasalar arasında, Çek ve Slovak anayasalarının mülkiyet hakkına ilişkin olarak devlete tanınacak istisnalar açısından yasama organına geniş bir takdir yetkisi tanıdığına da işaret etmek gerekir. Çek Cumhuriyeti Anayasası'na dahil Temel Haklar Şartı'nın, 11. maddesine göre, mülkiyet hakkına, tüm toplumun ihtiyaçlarının karşılanması, milli ekonominin ve kamusal refahın gelişmesi açısından getirelecek istisnalar yasayla belirlenir. Aynı şekilde, Slovak Anayasası'na göre, Slovak Cumhuriyeti'nde, m. 4'te sayılan milli servet niteliğindeki mallar dışında, toplumun ihtiyaçlarının karş1lanması, milli ekonominin ve kamusal menfaatin gelişmesi için elzem olan malların hangilerinin sadece devlet, topluluk veya belli tüzel kişilere ait olacağı yasayla belirlenir (m. 20/2).

Bütün bu anayasalarda mülkiyet hakkı diğer temel hak ve özgürlükler için geçerli olan sınırlama sebepleriyle sınırlanabilirken, Slovak Anayasası 
bunlara ek olarak bir takım spesifik sınırlama sebepleri öngörmüştür. Slovak Anayasası'na göre, mülkiyet hakkı, başkalarının zararına veya yasayla korunan genel menfaate aykırı biçimde kullanılamaz. Ayrıca mülkiyet hakkının kullanılması, yasayla belirlenen sınırları aşacak biçimde, insan sağlığ , doğa, kültürel varlıklar ve çevreye zarar veremez (m. 20/3).

Mülkiyet hakkının garanti altına alınması açısından, bu anayasalar da diğer temel hak ve özgürlükler için öngörülen koruma mekanizmaları mülkiyet hakkı için de geçerlidir. Ancak Polonya Anayasası bu mekanizmalara ek olarak, "hakkın özü" ölçütünü getirmekte ve mülkiyet hakkını biraz daha güvenceli bir statüye kavuşturmaktadır. Anayasa'nın 64. maddesine göre, mülkiyet hakkı ancak yasayla ve özüne dokunmaksızın sinırlanabilir.

Mülkiyet hakkı çerçevesinde, özelleştirme açısından önem taşıyan bir başka nokta, yabancıların mülk edinme hakkının tanınıp tanınmadığıdır. Özellikle yabancı yatırımcılara yönelik özelleştirme programları açısından hayati öneme sahip bu konuda, Slovak Anayasası hariç, incelemekte olduğumuz anayasalar suskun kalmaktadır. Slovak Anayasası ise olumsuz bir formülasyonla konuyu düzenlemekte ve yasa ile belli mallara sadece vatandaşlar veya Slovak Cumhuriyeti sınırları içindeki tüzel kişiler tarafından sahip olunacağının öngörebileceğini hükme bağlamaktadır. (m. 20/2) Bu konu, incelemekte olduğumuz ülkelerde genellikle yasalarla düzenlenmektedir.

Mülkiyet hakkı ile ilgili üzerinde durulması gereken son nokta, milli servet sayılan malların durmudur. İncelemekte olduğumuz anayasalar "milli servet" kavramına yer vermekte ve genellikle bu kategorideki malları devletin mülkiyetine dahil etmektedir. Dolayısıyla bu hükümler, söz konusu ülkeler açısından özelleştirilebilecek devlet mallarının anayasal sınırını çizmektedir. Macar Anayasası'na göre, Macar Devleti'nin mülkiyeti milli servet sayılır (m. 10-11). Slovak Anayasası'na göre, doğal zenginlikler, yeraltı suları, doğal şifalı sular ve su yolları Slovak Cumhuriyeti'ni mülkiyetindedir (m. 4). Çek Anayasası bu konuda daha esnek bir hüküm içermektedir. Anayasa'nın 7. maddesine göre, devlet milli kaynakların hakça kullanımını ve milli servetin korunmasını sağlamakla yükümlüdür.

(2) Özel Girişim Özgürlüğ̈̈ ve Devletin Ekonomik Hayata Müdahalesi: Özel mülkiyet hakkıyla yakından bağlantılı olan özel girişim özgürlüğü pazar ekonomisinin en temel unsurlarından birisidir. Serbest piyasa koşullarında bireylerin serbestçe ekonomik ilişkiye girebilmesi, mal ve hizmetlerin sahipleri tarafindan istenilen biçim ve şartlarda piyasaya sokulması pazar ekomisinin işlemesi için mutlaka var olması gereken şartlar arasındadır. Özel girişim özgürlüğü, bu anlamıyla, temel ekonomik faaliyetlerin bireyler tarafindan yürütülmesini, devletin ekonomik alandan çekilmesini de gerektirir. İncelemekte olduğumuz tüm anayasalar özel girişim özgürlüğünü garanti altına almaktadır (Çek Temel Haklar Şartı, m. 
26/1; Macar Anayasası, m. 9/2; Polonya Anayasası, m. 22, Slovak Anayasası, m. 55). Burada dikkat çeken bir nokta, söz konusu anayasaların özel girişim özgürlüğü açısından herhangi bir özel sınırlama sebebi öngörmemiş olmalarıdır. Bunun bir istisnası, Polonya Anayasası'dır. Polonya Anayasası'nın 22. maddesine göre, ekonomik faaliyet özgürlüğü ancak yasayla ve yalnızca çok önemli kamusal gerekçelerle sınırlanabilir. Bu düzenleme, özel girișim özgürlüğü açısından ek bir sınırlama nedeni getirmiş olsa da, maddenin formülasyonu ve "çok önemli kamusal gerekçe" ölçütü bu özgürlügün korunmasız kalması sonucunu doğuracak nitelikte değildir.

Devletin ekonomik hayata müdahalesinin anayasal sınırları nasıl çizilmelidir? Bu sorunun, literatürde ve uygulamada temel olarak iki model çerçevesinde cevaplandığını görüyoruz. "Neo-liberal" modele göre, devlet ekonomiden tamamen elini çekmeli ve devletin "yeniden-dağıtıcı" kapasitesi anayasal olarak sınırlanmalıdır. Bir başka deyişle, anayasa devletin ekonomik hayata müdahalesini engelleyecek hukuki bir set işlevi görmelidir. "Devlet-kapitalizmi" modeline göre ise, anayasa toplumun üretici gücünün gelişmesinde devletin vazgeçilmez yol gösterici rolünü tanıyacak biçimde tasarlanmalıdır. Bu model iki biçimde uygulanabilmektedir. Birinci biçimde, devlete piyasalara müdahale konusunda hiçbir esaslı sınırlama getirilmez. Örneğin A. V. Dicey'nin tasvir ettiğgi biçimiyle "Parlamento'nun üsütünlüğü" prensibine dayanan klasik İngiliz anayasal sistemi bu biçime yaklaşır. İkinci biçimde, anayasa açıkça devletin piyasalara müdahale edebilme kapasitesini telaffuz eder. Bu biçimin en tipik örnekleri Latin Amerikan anayasalarıdır (SCHNEIDERMAN, 2000).

$\mathrm{Bu}$ tipoloji çerçevesinde değerlendirildiğinde, Orta Avrupa anayasaları neo-liberal anayasacılığın unsurlarını taşımakla birlikte, Latin Amerikan anayasacılığına yaklaşmaktadır. Devletin piyasalara doğrudan müdahalesini sağlayan en önemli araçlardan biri olan kamulaştırma incelemekte olduğumuz anayasaların tümünde tanınmıştır. Ancak devlete bu yetki verilirken mülkiyet hakkı için de yeterli güvenece sağlanmıştır. İncelemekte olduğumuz anayasaların genel olarak kabul ettiği formülasyona göre, kamulaştırma ancak önemli veya kaçınılmaz bir kamu yararının olması durumunda yasayla ve bedeli adil bir biçimde ödenerek yapılabilir (Çek Anayasasına Dahil Temel Haklar Şartı, m. 11/4; Macar Anayasası, m. 13/2; Polonya Anayasas1, m. 21/2; Slovakya Anayasas1, m. 20/4). Bu düzenlemeler, Avrupa İnsan Hakları Sözleşmesi'ne Ek 1. Protokol ve Avrupa İnsan Hakları Mahkemesi içtihadıyla da uyum içindedir.

Devletin piyasalara müdahale edebilmesini sağlayan bir başka önemli araç merkez bankasının kontrolüdür. Günümüzde, siyaset bilimi ve ekonomi liteartüründe gittikçe artan bir biçimde merkez bankalarının siyasi iktidarlardan bağımsız olması gerektiğine dikkat çekilmektedir. İnceleme alanımzı olan Orta Avrupa'ya baktığımızda, Polonya Anayasası hariç, diğer anayasaların merkez bankasının tarafsızlığını ve bağımsızlığını anayasal 
düzeyde garanti altına alacak yeterli düzenlemeler içermediğini görüyoruz. Polonya Anayasası'na göre, Polonya Merkez Bankası Başkanı, Cumhurbaşkanının talebi üzerine, Sejm, yani Parlamento tarafından atanır. Anayasaya göre, Merkez Bankası Başkanı herhangi bir siyasi partiye ve sendikaya üye olamaz veya makamının vakarıyla bağdaşmayan herhangi bir kamusal faaliyette bulunamaz (Anayasa, m. 227). Orta ve Doğu Avrupa'daki diğer ülkelerde, anayasalardaki bu eksiğin genel olarak yasa düzeyinde yapılan düzenlemelerle büyük ölçüde giderildiğine de işaret etmek gerekir.

\section{Sonuç}

Sonuç olarak, Orta Avrupa deneyimi 1şı̆̆ında, özelleştirme ve anayasalar arasındaki ilişki konusunda şu temel tespitler yapılabilir: (1) Anayasal bir çerçeve olmaksızın, salt yasal düzenlemelerle özelleştirme faaliyetlerine girişilebilir, ancak bu faaliyetlerin yürütülmesi aşamasında yolsuzluk ve kayırmaların engellenmesi için anayasayla siyasi ktidara bir takım sınırlar çizilmesi şarttır; (2) Genel olarak ekonomik sistem, özel olarak özelleştirme konusunda anayasalar bir çerçeve çizmekle yetinmeli, ayrıntılar yasama ve yürütme organına bırakılmalıdır; (3) Özelleştirmenin yapılabilmesi için anayasalarda mülkiyet hakk1 ve özel girişim özgürlüğünün garanti altna alınması gerekir; (4) Özelleştirme faaliyetlerinin sağlıklı yürütülebilmesi için, devletin ekonomik hayata müdahalesine imkan veren kamulaştırma ve merkez bankasının kontrolü gibi konularda anayasada açı ve yeterli düzenlemelere yer verilmelidir. Özelleştime faaliyetlerinin liberaldemokratik rejimin çerçevesi içinde ve bu rejmin temel prensip ve kurumlarına zarar verilmeden yürütülmesi, bu faaliyetleri yürütenlerin söz konusu prensip ve kurumlara verdikleri önem kadar, yukarıda sayılan "anayasa mühendisliği” tedbirlerinin alınmasına da bağlıdır.

$$
* * * * *
$$

\section{KAYNAKÇA}

Angelov, Georgi G., "Legal Framework of Privatization in Russia," Minnesota Journal of Global Trade, 1993, s. 2-21.

Balfour, Michele ve Cameron Crise, "A Privatization Test: The Czech Republic, Slovakia and Poland," Fordham International Law Journal, 1993, s. 17-58.

Bugaric, Bojan, "Economic Reforms and the Rule of Law: Privatization in Central and Eastern Europe", Conference Paper, Institute of Macroeconomic Analysis and Development, International Conference, 1999, http://www.sigov.si/zmar/conference/9799/pdf99/bb.pdf 
Cohen, Stephen S. ve Andrew Schwartz, "The Tunnel at the End of the Light: Privatization in Eastern Europe,", The Transnational Lawyer, 1994, s. 7-34.

Elster, Jon, "Making sense of constitution-making," East European Constitutional Review, Spring 1992, Vol.1, No.1, s. 15-17.

Elster, Jon, "Constitution-making in Eastern-Europe: Rebuilding the Boat in Open Sea," Public Administration, 1993, Vol. 71, No. 1-2; s. 169-217.

Elster, Jon, Claus Offe ve Ulrich K. Preuss, Institutional Design in PostCommunist Societies, Cambridge University Press, 1998.

Gönenç, Levent, Prospects for Constitutionalism in Post-Communist Countries, Kluwer, 2002.

Hellman, Joel, "Constitutions and Economic Reform in the Postcommunist Transition," East European Constitutional Review, 1996, s. 46-56.

Herbiet, Michel, "The Legal Foundations of the Economic System During a Period of Transition from a Planned to a Market Economy" Report of the European Commission for Democracy through Law, 1994, http://www.venice.coe.int/docs/1994/CDL(1994)009-e.asp

Holmes, Stephen, "The Postcommunist Presidency," East European Constitutional Review, Vol.2, No. 4/ Vol 3, No. 1, 1993/1994, s. 3639.

"NOTE: Avenues for Investment in the Former Czechoslovakia: Privatization and the Historical Development of the New Commercial Code," Delaware Journal of Corporate Law, 1993, s. 889-922.

Sachs, J. ve K. Pistor. "Introduction: Progress, Pitfalls, Scenarios, and Lost Opportunities." The Rule of Law and Economic Reform in Russia içinde, (Der. J. Sachs and K. Pistor), Westview Press, 1997.

Sachs, Jeffrey D., Woo, Wing Thye ve Yang, Xiaokai, "Economic Reforms and Constitutional Transition", Working Paper, 2000, http://ssrn.com/abstract $=254110$

Schneiderman, David, "Constitutional Approaches to Privatization: An Inquiry into the Magnitude of Neo-liberal Constitutionalism", Law and Contemporary Problems, 2000, s. 63-90. 